\title{
A Spare-part Distribution Management Model for diesel Engine industry
}

\author{
Kong Lingbo, Yu Kaichao \\ Faculty of Mechanical and Electronic Engineering, Kunming University of Science and Technology \\ Kunming 650093, PR China \\ e-mail:limber_k@126.com
}

\begin{abstract}
Under the analysis of the current situation and existing problems related to the spare-part distribution management of diesel engine industry, especially the incoordination between service stations and agents, the paper establishes a model featured as the multi-level warehouse, with a view of integrating the information of the whole chain and all levels of diesel engine industry from global warehouse, marketing and basic data, and effectively solving the problems regarding the distribution management of diesel engine industry. In the end of the paper, the implementation of the model in a case company is specified.
\end{abstract}

Keywords- after marketing; spare-part; CRM; multi-level warehouse

\section{INTRODUCTION}

With the social development and at the support of the state policy, the past years witness the vigorous development in auto industry, in particular, farm and engineering vehicles. As a major fitting of those vehicles, the engine generally takes the form of diesel engine, which differs a lot from the gasoline engine in terms of the after service.

Nowadays, most after service of domestic diesel engine can be provided in local service stations appointed by the engine industries. Effective distribution management of spare-part is deemed as a key factor in cutting down service cost, improving service efficiency, boosting profits and comprehensive competitiveness of enterprises.

Currently, many domestic enterprises have realized the importance of after services, and great effort has been made to establish or improve CRM. However, most enterprises focus their attention on marketing, and some expensive infrequently-used spare-parts are overstocked.

\section{CHARACTERISTIC OF DIESEL ENGINE INDUSTRY}

As a major fitting of agro-machinery, mobile machinery and diesel-driven automobiles, diesel engine is mainly produced by engine enterprises separately from auto enterprise, and the after service is also separated.

The current situation is listed as follows:

\section{A. Distribution and after service}

Different from the $4 \mathrm{~S}$ model of cars, the after service of diesel engine is provided by service stations appointed by engine industries. The after service covers running-in maintenance, free maintenance for those under warranty and paid maintenance for those after warranty. The service stations mainly have two sources of supply for spare-parts: directly through engine manufacturer as well as their senior service center.

So, it is obvious that there are two major consuming channels of spare-parts: sale from agents and use by maintenance services. However, the two channels themselves are independent from each other, and there is no interaction or cooperation between them.

\section{B. Characteristic of spare-part distribution}

The major channels to spare-part distribution in engine industry:

- Through local agents: they sell spare-parts in retail or wholesale.

- Through service stations: each station keeps a certain amount of spare-parts in store to ensure daily maintenance. However, the storage amount as well as the type is usually determined by the station empirically, so it is hard to avoid those abovementioned problems.

- Through local service centers or directly through the manufacturers.

\section{Cost control}

Local agents and service stations compose of two major spare-part consumers, but the company delivers goods through separated channels because the two consumers take responsibility for different departments, which adds to the cost for allocation and transport.

\section{DEMAND ForeCAST MODEL}

In 2005, Syntetos put forward a demand classification rule which is simple and practical and its content is shown in following matrix. In the matrix, ADI (average demand interval ) is the average interval of demand; $\mathrm{CV}$ (coefficient of variation) is the variation coefficient of nonzero demand value which can reflect the change extent of demand. The formula can be represented as $C V(x)=\frac{\sigma}{\mu}$, among which, $\mu$ is the average value, $\sigma$ is the standard deviation. As ADI gets larger, the demand discontinuity gets more obvious, while as CV2(x) gets larger, the demand quantity gets more unstable. When $\mathrm{ADI}>1.32$, the demand possesses the obvious discontinuity, while when $\operatorname{CV} 2(x)>0.49$, the demand possesses the 
obvious instability. In this matrix, Part A stands for the unstable demand; Part B stands for the smooth demand; Part $\mathrm{C}$ stands for the block demand and Part D stands for the intermittent demand. In the course of after service, the demand of wear parts used in normal maintenance of engine belongs to Part B demand, while in the case of emergency maintenance or exceptional maintenance, the demand of infrequently-used parts has the features of the three kinds of demands: Part A, C and D, especially Part C and D.

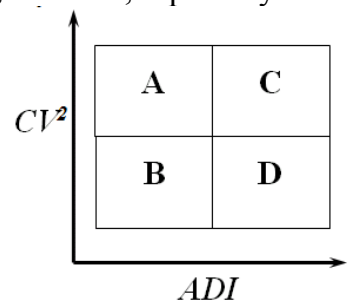

Fig.1 Demand Classification Rule of Spare-parts proposed by Syntetos

The demand forecast could be separated into two parts, namely demand quantity forecast and demand time forecast, and the final actual forecast result depends on the integration of the two parts. Its model could be explained in following chart.

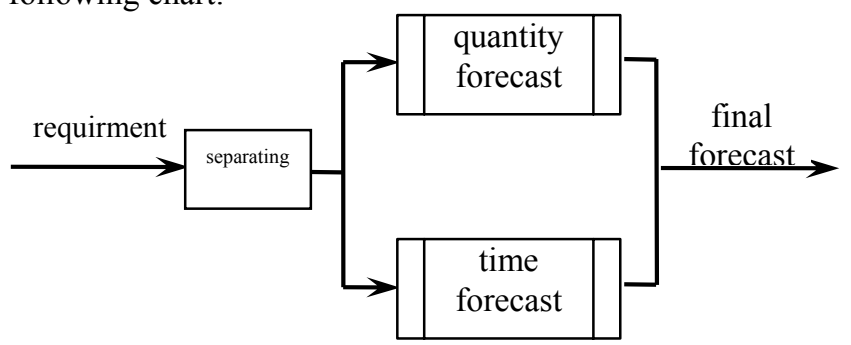

Fig. 2 forecast model for spare-part demand

\section{A. parameter}

$z_{t}$ is the actual demand value of the ${ }^{t}$ th month, and $z_{t}{ }^{\prime}$ is the forecast demand value of same month. $p_{t}$ is the forecast value of demand interval of the th month, and $q$ is the time lag from the last demand. $\alpha$ is the smoothness index, and its range is $0<\alpha<1$.

\section{B. forecast step}

First, $Z_{t}{ }^{\prime}$ is calculated based on the following model.

$Y=\left\{y_{1}, y_{2}, \cdots, y_{t}, \cdots\right\}$, among which, $t$ is used to count months, $y_{t}$ indicates the maintenance ratio of the complete sets in the th month after sold. $y_{t}$ can be gained through the historical maintenance data contained in after service module of CRM system.
$X=\left\{x_{1}, x_{2}, \cdots, x_{t}, \cdots\right\}$, as $x_{t}$ represents the number of the sold complete sets from the th month to now.

Therefore, the amount of spare-parts in need can be calculated as:

$$
z_{t}{ }^{\prime}=\beta \sum_{j=1}^{t} x_{j} y_{j} \text {, among which, } \beta \text { is the maintenance }
$$

ratio of certain material in the engine machine, and it can also be obtained through statistic analysis from the data of CRM system.

Then, smoothness index can be forecasted:

if $z_{t}=0$

$$
\begin{aligned}
& \text { then } z_{t}{ }^{\prime}=z_{t-1}{ }^{\prime}, \quad p_{t}{ }^{\prime}=p_{t-1}{ }^{\prime}, q=q+1 \\
& \text { if } z_{t} \neq 0 \\
& \text { then } \quad z_{t}{ }^{\prime}=z_{t-1}{ }^{\prime}+\alpha\left(z_{t}-z_{t-1}{ }^{\prime}\right)
\end{aligned}
$$

$p_{t}^{\prime}=p_{t-1}{ }^{\prime}+\alpha\left(q-p_{t-1}{ }^{\prime}\right), \quad q=1$

After the comprehensive consideration of demand quantity forecast and demand interval forecast, the forecast value of final average demand in certain period can be calculated as:

$$
z_{t}^{*}=\frac{z_{t}{ }^{\prime}}{p_{t}{ }^{\prime}}
$$

When demand happens, or $Z_{t} \neq 0$, the value of $Z_{t}^{*}$ would be updated.

\section{MODEL}

\section{A. Framework of global warehouse}

In order to solve the problems mentioned above, a multilevel warehouse model is suggested to set up, including central warehouse, regional warehouse and terminal warehouse which is embodied as agents and service stations. The framework is as follows:

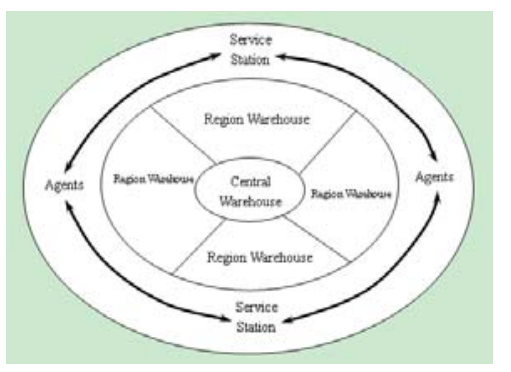

Fig.5 A model of multi-level warehouse

To fulfill the intended function, the warehouse should be configured as follows:

- Product management type

In view of the facts mentioned, the warehouse should be classified into two kinds according to the product type: one is the complete engine warehouse attached to the 
automobile enterprise, and the other is spare-part warehouse targeting the after service.

- Multi-level warehouse type

The warehouses are hierarchically leveled as: central warehouse, regional ones, customer/final ones, etc.. The customer/final warehouse includes agents and service stations. Such grading is based on the application level and the management range.

When an order is accepted, CRM system will first list the sequence parameter of regional distribution based on the regional distribution of produced engine. In the formula of $C=\left\{c_{1}, c_{2}, \cdots, c_{k}\right\}, c_{k}$ stands for the proportion of engines sold to certain region in total sold engines. Consequently, the following formula can be referred to calculate the desired quantity of spare-parts which should be stored in this region.

$$
Z^{*}=d \cdot Z \bullet C
$$

among which, $d$ is the regional index, considering the maintenance ratio of engine is different in different regions due to the diversity of their terrain and climate.

- Attributes of stock management

Besides ordinary attributes, the multi-level warehouse can be featured as the follows: apanage, higher and lower levels, proprietary rights, etc.

- Monitor and control

We put forward the following ways for daily management:

$>$ Classify the spare-parts using $\mathrm{ABC}$ Classification, and monitor them respectively.

$>$ Provide agents and service stations with relevant reference data according to statistical analysis toward the CRM system.

$>$ Strengthen the bond between local agents, service stations and service centers.

In $\mathrm{ABC}$, we could use the following formula:

$P_{i}=\left(Q_{i} \times e_{i} / \sum_{j=1}^{n} Q_{j} \times e_{j}\right) \times 100 \%$

$P_{i} \longrightarrow$ current proportion of No. $i$ spare-part in total stock, $i=1,2, \cdots, n$;

$Q_{i} \longrightarrow$ current stock quantity of No. $i$ spare-part, $i=1,2, \cdots, n$;

$$
e_{i} \_ \text {current price of No. } i \text { spare-part, } i=1,2, \cdots, n \text {; }
$$

$$
\Delta_{i}=\frac{P_{i}-P_{i 0}}{P_{i}} \times 100 \%
$$

In above formula, $\Delta_{i} \longrightarrow$ kinetics of current proportion of No. ${ }^{i}$ spare-part in total stock, $i=1,2, \cdots, n$;

$P_{i 0}$ initial proportion of No. ${ }^{i}$ spare-part in total stock, $i=1,2, \cdots, n$;
When it is put into practice, the upper limit of $\Delta_{i}$ can be fixed. If the $\Delta_{i}$ value of certain spare-part exceeds the fixed range, warehouse keeper should consider classifying Part A, B and C again. Therefore, the model realizes the dynamical maintenance of spare-part classification, and ensures the classification desirable and real-time.

\section{B. Global marketing information}

Based on the multi-level warehouse and the information system, the model could realize the sharing of global marketing information. The corresponding agents, service stations and service centers could conditionally share the sale and inventory information which is of utmost business secrecy, including the in stock amount of particular spareparts, unified price, customer satisfaction, etc.

\section{Basic data Management and updating}

The basic data is viewed as the solid guarantee for the successful operation of any information system, and meanwhile, the foundation for close cooperation and exchange among departments. To ensure the successful implement of the model in diesel engine industry, the basic data should be completed and integrated.

\section{CONCLUSION}

Spare-part business covers purchasing, stocking and distributing. Taking diesel engine industry as an example, the paper gave an introduction on the distribution management of spare-parts. The distribution management of engine industry and automobile industry has some characteristic in common, and also distinguishable. After analyzing the current situation and existing problems of distribution management in diesel engine industry, the paper put forward a model for solution. In the last part of the paper, a case company was given to specify the implementation of the model, which proved the feasibility and practicability of the model.

Based on the general model proposed by the paper, further research are still needed to solve some other problems, particularly how to combine the model with the existing management information system to realize the integration of data and business, and then reduce data redundancy and isolated information.

\section{ACKNOWLEDGEMENT}

It is funded by one of the major projects of Yunnan Provincial Development and Reform CommissionDevelopment and Application of customer relationship management system of yunnei power. YDRC high-tech [2004], NO.1083.

\section{REFERENCE}

[1] Kong Lingbo, Yu Kaichao, "Research on the customer service system for diesel engine industry”, IE\&EM 2009, pp.1380-1383, 2009.10. 
[2] Petri Suomala, Matti SievaKnen*, Jari Paranko, "The effects of customization on spare part business-A case study in the metal industry", Int. J. Production Economics 79 (2002) 57$\} 66$

[3] Sleptchenko, M.C. van der Heijden, A. van Harten, "Using repair priorities to reduce stock investment in spare part networks", European Journal of Operational Research 163 (2005) 733-750

[4] Uwe Dombrowski, Johannes K. Wrehde, Sven Schulze, "Efficient spare part management to satisfy customers need"

[5] B Azvine, D D Nauck, C Ho, K Broszat and J Lim, "Intelligent process analytics for CRM", BT Technology Journal • Vol 24 No 1 • January 2006 [6] So Young Sohn , Ji Soo Lee, "Cost of ownership model for a CRM system”, Science of Computer Programming 60 (2006) 68-81 